\title{
A influência do diagnóstico de autismo na trajetória profissional das mães da Grande
}

\section{Florianópolis}

\author{
The influence of the diagnosis of autism on the professional path of the mothers of Florianópolis \\ La influencia del diagnóstico del autismo en el camino profesional de las madres de La Gran \\ Florianópolis
}

Recebido: 20/04/2021 | Revisado: 27/04/2021 | Aceito: 03/05/2021 | Publicado: 16/05/2021

Luiara Santiago Borges

ORCID: https://orcid.org/0000-0002-2589-8684 Universidade Federal de Santa Catarina, Brasil E-mail: luiarasantiagoborges@gmail.com

Marcos Baptista Lopez Dalmau

ORCID: https://orcid.org/ 0000-0002-8620-1625 Universidade Federal de Santa Catarina, Brasil E-mail: professordalmau@gmail.com

\begin{abstract}
Resumo
As Mulheres que se tornam mães e se deparam com o diagnóstico de autismo dos filhos, tem que adequar a vida à uma nova realidade. Dentro dessa mudança, inclui-se o assunto carreira profissional, no qual podem ou não interrompê-la ou até mesmo mudá-la em função da situação. Diante do exposto, o objetivo deste trabalho foi o de compreender a influência do diagnóstico de autismo do filho sobre a trajetória profissional das mães pertencentes à região da Grande Florianópolis. No que tange à metodologia, informa-se que foi um estudo aplicado, exploratório e quantitativo. Como estratégia de coleta de dados, utilizou-se de um questionário com 76 questões, sendo o mesmo enviado para 379 mães de autistas. O contingente de respondentes foi compatível com a amostra mínima projetada. Os resultados mostraram os perfis e as mudanças ocorridas após o recebimento do diagnóstico dos filhos o que, ao final, permitiu-se a identificação de similaridades e disparidades das trajetórias profissionais destas mulheres, o que permitiu o entendimento de suas escolhas.
\end{abstract}

Palavras-chave: Gestão de pessoas; Carreira profissional; Mãe de autista.

\begin{abstract}
Women who become mothers and are faced with their children's autism diagnosis, have to adapt life to a new reality. Within this change, the subject of professional career is included, in which they may or may not interrupt it or even change it depending on the situation. Given the above, the objective of this study was to understand the influence of the child's autism diagnosis on the professional trajectory of mothers belonging to the Greater Florianópolis region. Regarding the methodology, it is reported that it was an applied, exploratory and quantitative study. As a data collection strategy, a questionnaire with 76 questions was used, which was sent to 379 mothers of autistic children. The contingent of respondents was compatible with the minimum projected sample. The results showed the profiles and changes that occurred after receiving the children's diagnosis, which, in the end, allowed the identification of similarities and disparities in the professional trajectories of these women, which allowed them to understand their choices.
\end{abstract}

Keywords: People management; Professional career; Autistic mother.

\section{Resumen}

Las mujeres que se convierten en madres y se enfrentan al diagnóstico de autismo de sus hijos, tienen que adaptar la vida a una nueva realidad. Dentro de este cambio se incluye la asignatura de carrera profesional, en la que pueden o no interrumpirla o incluso modificarla según la situación. En vista de lo anterior, el objetivo de este estudio fue comprender la influencia del diagnóstico de autismo del niño en la trayectoria profesional de las madres pertenecientes a la región del Gran Florianópolis. En cuanto a la metodología, se informa que fue un estudio aplicado, exploratorio y cuantitativo. Como estrategia de recolección de datos se utilizó un cuestionario con 76 preguntas, el cual fue enviado a 379 madres de niños autistas. El contingente de encuestados fue compatible con la muestra mínima proyectada. Los resultados mostraron los perfiles y cambios que ocurrieron luego de recibir el diagnóstico de los niños, lo que, al final, permitió identificar similitudes y disparidades en las trayectorias profesionales de estas mujeres, lo que les permitió comprender sus elecciones.

Palabras clave: Gestión de personas; Carrera profesional; Madre autista. 


\section{Introdução}

A mulher e a carreira profissional são algo recente na história, pois o papel feminino foi visto pela sociedade durante muitos anos como algo inerente às rotinas do lar, ou que tem a função cuidar da casa, filhos, marido e da família como um todo. Porém, a crescente do papel feminino no mercado de trabalho ao longo dos últimos anos proporcionou várias pesquisas e estudos no campo das Ciências Sociais Aplicadas conforme entendimento de Magalhães na obra de Ceribelli e Silva (2017).

As mulheres pós-modernas, conforme visão de Simões e Hashimoto disponível no trabalho de Ceribelli e Silva (2017), vêm enfrentando novos desafios acerca da maternidade e carreira profissional, sendo levadas a dúvida de serem mães e se dedicarem integralmente (ou conciliarem) a carreira profissional e família, ou por até mesmo tomar a decisão de não serem mães e priorizarem a carreira.

Há um número representativo de mulheres (30\%) que deixaram seu posto de trabalho para cuidar dos filhos, conforme aponta uma pesquisa realizada pela Catho em 2018. Tal pesquisa apontou também que $48 \%$ das mães afirmaram que já enfrentaram problemas no trabalho por terem que se ausentar porque o filho ficou doente (Trevisan, 2019).

Dentro deste cenário materno, ainda existem mulheres que se depararam com um diagnóstico de Transtorno do Espectro Autista (TEA). Para tanto, a tomada de decisão relacionada à carreira profissional pode apresentar um desafio ainda maior para estas mulheres, pois com a chegada do diagnóstico vem as incertezas, as preocupações, o que resulta em um repensar da própria vida.

Apesar do autismo estar em evidência na mídia no momento atual, esta patologia ocorre com uma grande incidência. Conforme a Organização Pan-Americana da Saúde (OPAS), uma a cada 160 crianças no mundo têm TEA, sendo que este começa na infância e dura até a fase adulta (OPAS, 2017). Ainda que não se tenha um número exato de autistas no Brasil, em 2018 se realizou um Censo da Educação Superior, coordenado pelo Instituto Nacional de Estudos e Pesquisas Educacionais Anísio Teixeira (Inep). Neste levantamento, verificou-se que haviam, por exemplo, 488 alunos com TEA nas universidades brasileiras. Destes, 212 encontravam-se em instituições de ensino públicas e outros 276 em privadas, embora as dificuldades de interação e relação social não impediram que autistas pudessem traçar suas carreiras profissionais, sendo isso possível com a ajuda das terapias, professores da escola e a família (Tenente, 2018).

Para poder compreender melhor sobre o autismo, é importante entender o que é TEA. Este transtorno é caracterizado por uma dificuldade que abrange a interação social, a alteração na comunicação e padrões limitados ou estereotipias (repetição inconsciente) de comportamentos e interesses. Sendo o seu grau bastante variado, podem existir casos muito severos, comprometendo drasticamente a capacidade laboral das pessoas. Contudo, sabe-se que em muitos casos é possível se ter uma boa qualidade de vida (Leopoldino, 2015).

O indivíduo diagnosticado com TEA ao longo de toda a sua vida deverá ter intervenção terapêutica. Devido aos comprometimentos comportamentais do Autista, na maioria das vezes a mãe é quem acaba responsável por dar esse suporte. Todas as semanas são vários profissionais para as mais diversas terapias que a criança necessita, e, diante de dilemas como este, é que várias mães se deparam em mudar ou ajustar a sua carreira profissional a fim de conciliar suas carreiras ao tratamento de seus filhos (Bosa, 2006).

Se vendo nessas situações, muitas mães largam o emprego para poderem ser as terapeutas dos filhos a fim de minimizar os danos e suprirem as faltas de terapias não ofertadas pelo SUS por exemplo, ou acabam investindo na carreira para que possam suprir os tratamentos e fazerem os pagamentos de sessões particulares/complementares das terapias.

A decisão de continuar a carreira profissional, trocar de profissão, ou simplesmente largar tudo, vai muito além do quesito financeiro. Acredita-se, também, que existe a questão emocional envolvida. A questão de ter filho autista e todos os cuidados que implicam para a criança faz com que as mães repensem suas vidas profissionais. 
Diante do exposto, para realizar esta pesquisa será considerado como público-alvo as mães de autistas residentes na região da Grande Florianópolis por ser esta uma região onde o número é bastante expressivo no Estado. Justamente diante deste cenário é que surge a pergunta de pesquisa que se pretende responder ao longo deste artigo: Como o diagnóstico de autismo do filho influenciou a trajetória profissional das mães que residem na Grande Florianópolis?

Para que se possa responder à pergunta de pesquisa, definiu-se como objetivo geral: compreender a influência do diagnóstico de autismo do filho sobre a trajetória profissional das mães que residem na Grande Florianópolis.

\section{Fundamentação Teórica}

Esta seção apresenta os pressupostos teóricos que embasam este estudo compreendendo temas como: trabalho, empregabilidade, mulher/mãe e a carreira profissional e TEA - autismo.

\subsection{Trabalho, empregabilidade, a mulher/mãe e a carreira profissional}

Ao conceituar trabalho, não se pode limitar apenas ao vínculo empregatício, a ocupação ou suas contribuições para o desenvolvimento da humanidade desde o início dos tempos conforme pensamento de Carvalho e Marcelino (2019).

A relação homem e trabalho esteve em constante dinâmica ao longo dos anos, tendo sua variação de acordo com a época e sistema social vigente, e a história demonstra que as transformações no trabalho exerceram uma forte influência na construção da sociedade (Brito, 2020).

Com a entrada do regime econômico capitalista, o trabalho mudou a forma de ser tratado, e a relação de prestação de serviço passou a ter um vínculo duradouro com seu contratante. Iniciou-se nesta fase o trabalho assalariado, expressão adotada a partir do capitalismo, no qual insere o prestador de serviço em uma organização, a fim de explorar o lucro, subordinado a uma mão de obra (Moura, 2016). Porém o período de industrialização e as mudanças no trabalho se começou a compreender a administração e ocorreu o surgimento da teoria administrativa.

Foi a partir da evolução da organização, que surge o conceito de empregabilidade, tendo a origem do conceito na década de 1950, mas foi apenas no ano de 1990, que se deu o processo de investigação empírica do seu significado, e a noção de seu conceito sofreu diversas transformações conceituais.

Os estudos acerca de empregabilidade compreendem o termo em três níveis analíticos distintos, sendo o primeiro em uma abordagem societal, predominando no ano de 1970, sendo entendida como um indicador das oportunidades de trabalho. O segundo nível é uma compreensão da década de 80 , que se trata das múltiplas formas de vínculo empregatício a organização. O último nível traz uma ressignificação para o conceito de empregabilidade, se tornando um indicador sobre a possibilidade de se adquirir um emprego, se mantendo atrativo para o mercado interno e externo de trabalho, sendo este adotado até os dias atuais (Peixoto et al, 2015).

Devido às mudanças que vêm sendo geradas aos trabalhadores, ocorreu a necessidade de estar adquirindo novas competências a fim de se tornar um profissional de sucesso do século XXI. Conforme Ciampa et al (2014), a evolução deste profissional é um processo sucessivo e gradual, que ocorrerá de acordo com os arranjos tanto da vida pessoal, quanto da vida profissional. Em outras palavras, entendimentos que vão ao encontro do conceito de carreira profissional.

A carreira profissional, segundo Medina (2016), se refere à tomada de decisões do trabalhador que geram eventos determinantes para a sua trajetória profissional. Porém, não se trata de uma simples sequência linear de experiências vividas pelo indivíduo, mas sim uma consequência da relação entre a necessidade do sujeito e das organizações, considerando a inserção de ambos em um contexto mais amplo que geraram esta relação.

Considerando todo o escopo apresentado, insere-se mais um ponto cuja discussão e estudos retornou à pauta: a inserção das mulheres no mercado de trabalho, bem como sua carreira profissional. 
Apesar de inúmeras lutas femininas e leis que protejam a mulher no mercado de trabalho, ainda existem preconceitos ligados ao estereótipo feminino, que vê a mulher como mãe, cuidadora, uma pessoa incapaz de lidar com desafios (Machado, 2018). Porém, a mulher quando se torna mãe adquire inúmeras qualidades, que a tornam mais capaz para os desafios enfrentados no mundo corporativo.

Quando a mulher que está no mercado de trabalho ascende em sua carreira, ela começa a ter que lutar contra muitos estereótipos ou então vivencia uma grande desvantagem em termos de recompensas pelo seu trabalho. A partir do momento em que se torna mãe, ela passa a carregar não apenas a responsabilidade de ser uma "boa" mãe, da mesma forma, um peso a mais pela possibilidade de fracassar na conciliação de sua carreira profissional com a vida materna conforme pontos de vista de Badinter (1985) e Carvalho Neto et al (2014 como citado em Santos et al., 2019).

Em alguns casos, a mulher quando se torna mãe pode chegar a interromper a jornada da sua carreira profissional, ou então ficar desmotivada por largar seu emprego. Porém, apesar disto, tem se mostrado um número expressivo de mulheres que retornam ao trabalho após a gravidez, apesar das dificuldades mostradas pelo mercado de trabalho e as barreiras que a sociedade impõe (Julião et al., 2019).

Alguns dos desafios no qual a mulher-mãe trabalhadora vem passando é com relação aos olhares dos empregadores após a volta da licença maternidade, com relação às necessidades que as mulheres têm que sair em caso de doenças do filho, ou de ligações durante o expediente para poder acompanhar o que está acontecendo com o filho, mas estas situações tendem a diminuir à medida que a criança cresce e depende menos dos cuidados maternos (Julião et al., 2019).

Dentre outros desafios da mulher e a sua formação na carreira profissional, a maternidade é a que mais interfere, principalmente quando os filhos são pequenos. Mesmo com a ascensão da mulher no mercado de trabalho e as transformações políticas, sociais e econômicas no Brasil, as atividades domésticas continuam sendo de responsabilidade feminina segundo Bruschini (2000 como citado em Santos et al., 2019).

Com isso, a mulher-mãe passa um misto de sensações, variando desde a culpa pelo cansaço por não terem com quem dividir as demandas do lar, e deste modo, vive um conflito em equilibrar a vida pessoal com a profissional (Salvagni e Canabarro, 2015; Carvalho Neto et al (2007 como citado em Santos et al., 2019), como pelo crescimento na carreira profissional sem ter que renunciar a maternidade, em função da possibilidade de conciliar as tarefas no lar e as responsabilidades inerentes aos filhos ou a existência de uma rede de apoio de acordo com Fiorin el tal (2014 como citado em Santos et al., 2019) e visão de Pinto (2015).

\subsection{Transtorno do Espectro Autista e mãe de autista}

O Transtorno do Espectro Autista, conhecido como TEA, é um transtorno do neurodesenvolvimento, no qual compromete algumas funções neurológicas, que não se desenvolvem como deveriam, nas regiões cerebrais das pessoas acometidas, por esta patologia. O TEA, é ainda uma condição muito complexa, tendo vários fatores que contribuem para o risco (Gaiato, 2018).

A palavra Autismo vem da palavra grega autos, que significa eu mesmo, dando uma noção de próprio, de si próprio. Mas este transtorno do neurodesenvolvimento é caracterizado por uma dificuldade de comunicação, na interação social e a presença de padrões restritivos e repetitivos (American Psychiatric Association como citado em Montenegro et al., 2018).

No entanto, conforme Gaiato (2018, p.15), o nome Transtorno do Espectro Autista, a patologia dá uma ideia de amplitude variedade, pois "assim como um espectro de cor é a decomposição da cor branca, o do autismo também passa por uma variedade de sintomas nas áreas de comunicação social e de interesses restritivos”. 
Mas o diagnóstico de autismo se deu em 1943 pelo Médico Leo Kanner, que foi o pioneiro na psiquiatria infantil, e propôs um artigo intitulado "Autistic disturbances of affective contact”, em uma tradução literal, Distúrbios Autísticos do contato afetivo (Grandin, 2015).

Uma das descobertas de Kanner durante o experimento foi que as crianças tinham um dos pais extremamente bemsucedido, e isso levou na década de 50 ao conceito de "mãe-geladeira", no qual o transtorno estava ligado ao trauma do filho de um baixo vínculo parental de negligência dos pais. Porém na década de 70, foi esclarecido que o autismo tinha forte base genética e cerebral, e as interações educacionais e comportamentais, seriam as estruturas para que as crianças possam aprender (Volkmar \& Wiesner, 2019).

Mas em 1987, a terceira revisão do DSM, abreviação de Diagnostic and Statistical Manual of Mental Disorders (Manual diagnóstico e estatístico de transtornos mentais), o diagnóstico de autismo mudou e o nome de autismo infantil para transtorno autista, expandindo também o número de critérios de diagnósticos de seis para dezesseis, e dividiu em três categorias e para uma criança ser enquadrada no diagnóstico, deveria portar 8 sintomas, e este novo enquadramento aumentou os índices do diagnóstico (Grandin, 2015).

No entanto, somente no DSM-IV de 1994 que se acrescentou a Síndrome de Asperger e aumentando ainda mais o diagnóstico de autismo. Com a revisão do DSM-IV em 2000, pessoas diagnosticadas com transtorno global do desenvolvimento, foram enquadradas com TEA, é com isso ocorreu uma ideia de "epidemia" de autista (Grandin, 2015).

Porém o TEA não é tão incomum, e possui uma prevalência estimada de $1 \%$ a $2 \%$ entre crianças e adolescentes, conforme pesquisas internacionais nos Estados Unidos, Europa e Ásia, como também, sua ocorrência é maior entre meninos, sendo afetado cerca de quatro meninos para cada menina (Gaiato \& Teixeira, 2018).

Apesar de já haver vários estudos sobre como uma pessoa pode ter autismo, estudos de bases neurobiológicas ainda não chegaram em um consenso de um marcador biológico que possa identificar o autismo, e também não existe nenhum exame de sangue ou encefalograma que possa identificar o autismo. Por isso, ainda é o diagnóstico clínico baseado em critérios comportamentais estabelecidos pela DSM que determina se uma pessoa se encontra no espectro autista ou não (Fontoura, 2015).

Uma mãe, ao gerar o filho, cria sobre esta criança expectativas do seu futuro, e ao nascer, acaba se deparando com uma realidade que muitas vezes não é igual a idealizada. Muitas vezes a mãe se depara com uma diagnóstico de autismo e com as dificuldades inerentes aos cuidados na medida em que a criança vai crescendo, o que tende a gerar frustrações e priorizações diferentes das voltadas para a questão da carreira profissional (Rodrigo et al como citado em Ferreira et al., 2018).

\section{Procedimentos Metodológicos}

Para este capítulo, serão apresentadas as definições e escolhas metodológicas utilizadas para a elaboração desta pesquisa.

No que tange a definição do tipo de estudo, foram utilizados os seguintes elementos utilizados conforme visão de Almeida (2014): Natureza, objetivos, abordagem e procedimentos.

Nesse sentido, quanto a sua natureza, esta pode ser considerada como uma pesquisa aplicada, no qual gerou conhecimento com aplicação prática para as soluções de problemas específicos (Prodanov, 2013).

O objetivo do estudo foi de cunho exploratório de acordo com Lozada e Nunes (2018), a partir do ponto em que se buscou estudar assuntos pouco explorados sob a ótica em tela e para se ter uma visão geral da realidade das mães de autistas no âmbito profissional.

Com relação à abordagem da pesquisa, esta foi predominantemente quantitativa, pois segundo Almeida (2014), se trabalhou com a percepção de diversos sujeitos específicos e aderentes ao tema central do trabalho. 
No tocante referente ao procedimento da pesquisa, utilizou-se como base os conceitos inerentes à uma pesquisa de levantamento, onde este tipo de pesquisa se caracteriza pela interrogação das pessoas em que se deseja conhecer o comportamento, assim como se propõe "a solicitação de informações a um grupo significativo de pessoas acerca do problema estudado para, em seguida, mediante análise quantitativa, obterem-se as conclusões correspondentes aos dados coletados" (Gil, 2018, p. 33).

Para a definição dos sujeitos desta pesquisa, considerou-se a aderência dos mesmos frente aos seguintes objetivos específicos a saber:

Quadro 1 - Sujeitos do estudo.

\begin{tabular}{|l|l|}
\hline Objetivos Específicos & Sujeitos \\
\hline $\begin{array}{l}\text { a) Mapear o perfil profissional das mães de autistas que residem na região da Grande } \\
\text { Florianópolis; }\end{array}$ & $\begin{array}{l}379 \text { mães de autistas que estão } \\
\text { nos grupos de WhatsApp sobre } \\
\text { autismo. }\end{array}$ \\
\cline { 1 - 1 } b) Analisar as mudanças ocorridas após o recebimento do diagnóstico de autismo do(a) filho(a); & \\
\cline { 1 - 2 } $\begin{array}{l}\text { c) Identificar as similaridades e disparidades da trajetória profissional das mães de autistas que } \\
\text { residem na região da Grande Florianópolis; }\end{array}$ & \\
\hline
\end{tabular}

Fonte: Autores.

Como regra de cálculo para o dimensionamento do universo de pesquisa, selecionou-se os sujeitos pertencentes aos 6 (seis) grupos de WhatsApp existentes nos municípios pertencentes à Grande Florianópolis. A escolha pelos grupos se deu por causa que a pesquisadora autora deste trabalho participa ativamente dos mesmos e, em especial, por ter um filho com autismo.

Para conhecimento, os grupos são: a) Pais Projeto Levi, com 22 membros; b) Conversando sobre autismo 01, com 212 membros; c) Grupo Pais 1 - Apae São José, com 61 membros; d) Conversando sobre autismo 02, com 19 membros; e) Grupo Autistas de São José com 4 membros; e f) Lindo Balão Azul, com 61 membros.

Ressalta-se que neste quantitativo de 379 pessoas, o resultado foi estimado mediante cuidados para se evitar as repetições de nomes, bem como por levar em consideração apenas os números com o DDD 48, que é o código de área da região atendida.

Quanto ao cálculo da amostra, salienta-se que ele foi determinado de acordo com Mattar (2014), mediante cálculo baseado pela utilização da seguinte fórmula:

$$
n=\frac{N Z^{2} P Q}{e^{2}(N-1)+Z^{2} P Q}
$$

Para efeito de esclarecimentos, "P é a proporção da ocorrência da variável da população; "Q" é a proporção não correspondente, sendo recomendável ter uma população mais homogênea; "N" é o tamanho da população; "Z" é igual ao nível de confiança; e "e" é o erro amostral.

Diante do exposto, temos P com o valor de $80 \%$ e Q representando 20\%. O valor de N é o tamanho da população, que conforme apresentado anteriormente, corresponde a 379 membros nos grupos de WhatsApp. O nível de confiança determinado (Z) foi de $90 \%$. Logo, temos o valor de 1,645 que com a definição de um erro amostral (e) de $8 \%$, resultou no número final arredondado mínimo de 58 mães de autistas para responderem à pesquisa.

Visando coletar os dados, adotou-se a utilização de um questionário que foi elaborado levando em consideração cinco focos de análise: Perfil Socioeconômico da mãe, Perfil profissional, Mudanças profissionais em função do diagnóstico, Lacunas profissionais e Plano de carreira, totalizando 76 perguntas. As perguntas foram inseridas no Google Forms por possibilitar uma aplicação mais fácil, rápida e abrangente a um público com tais características. 
Antes, porém, realizou-se um pré-teste com 3 mães de autistas no intuito de verificar se as questões delineadas possibilitariam um entendimento claro sobre o que se pretendia. Após recomendações sugeridas e realizadas as devidas alterações, o questionário foi divulgado no dia 18 a 30 de outubro de 2020.

Como forma de divulgação foram utilizados os grupos já mencionados sobre autismo do WhatsApp, no qual se fez uma divulgação mais assertiva em três datas distintas: 18, 21 e 26 de outubro de 2020. Ainda no intuito de se obter o máximo de participação possível, encaminhou-se mensagens privadas para todos os membros destes grupos. Em paralelo, utilizou-se a estratégia de posts no stories do Instagram, sendo marcados profissionais da saúde e pedagogas para a divulgação do questionário.

Como resultado da pesquisa, totalizou-se, inicialmente, 121 respostas. Porém, após análise preliminar das mesmas, verificou-se que 12 destas não pertenciam à mães de autistas, assim como 30 eram provenientes de pessoas que não residiam na região territorial delimitada. Desta forma, após eliminação destes dados incompatíveis, chegou-se ao número final de 79 respostas válidas para a pesquisa, o que fez com que o nível de confiança subisse para $90 \%$.

Para a análise de dados utilizou-se de técnicas estatísticas simples e descritivas para poder realizar a interpretação dos dados coletados.

\section{Apresentação dos Resultados e Discussão}

Nesta etapa da pesquisa será apresentada a análise e discussão dos dados e resultados alcançados na pesquisa, levando em consideração os objetivos específicos determinados.

\subsection{Perfil profissional das mães de autistas}

Para iniciar a pesquisa e traçar o perfil profissional das mães, foram identificados os fatores socioeconômicos das mães de autistas. Com relação ao município de residência, a maior parte das mães respondentes pertence ao município de São José, sendo um total de $64,6 \%$, e apenas $35,4 \%$ dos respondentes do município de Florianópolis.

Com relação à faixa etária, a maior incidência encontrada foi entre 31 e 40 anos com 41,8\%, seguido pela faixa entre 41 e 50 anos com o percentual de $38 \%$, com percentuais de $11,4 \%$ para a faixa etária entre 21 e 30 anos, de 6,3\% para a faixa etária acima de 51 anos, e por último a faixa etária com menos de 20 anos, representando 2,5\%.

Quanto ao estado civil das respondentes, observa-se que 45,6\% das mães de autistas são casadas. Em seguida aparece o percentual de $25,3 \%$ referente à união estável. Depois tem-se $17,7 \%$ de solteiras, $10,1 \%$ de divorciadas e apenas $1,3 \%$ de viúvas. O estado civil casado e união estável ocupam mais de $70 \%$ da faixa percentual, mostrando que a maioria das mães têm uma pessoa companheira, podendo isso ser refletido na relação ao apoio familiar.

Com relação à escolaridade das mães 60,7\% das mães possuem pelo menos ensino superior completo, proporcionando a oportunidade de uma melhor qualificação no mercado de trabalho. Com relação a ter pelo menos o ensino médio completo, se tem uma parcela de $31,7 \%$, no qual se tem oportunidades de trabalho mais operacionais (segundo relatos), e apenas uma pequena parcela de mães - equivalente a 7,6\% - não possui o ensino médio completo, o que ocasiona, por vezes, uma maior dificuldade quando se analisa situações de recolocação e salários pagos no mercado de trabalho da região.

A fim de compreender melhor sobre as escolhas profissionais e os reflexos no diagnóstico do filho, verificou-se a escolha dos cursos das mães. Para tanto, o mais optado foi o curso de Pedagogia, representado pela maior incidência - 12 mães da amostra. Uma possível justificativa é que em função do diagnóstico do filho tal escolha foi feita, visto que a maior dificuldade do autista é a interação social e a pedagogia é uma área que vem agregar muito para o tratamento, dando a oportunidade para a mãe ter conhecimentos específicos e assim conseguir auxiliar o filho no seu desenvolvimento. Contudo, 
analisando as respostas de maneira mais ampla, percebeu-se que o diagnóstico não influenciou diretamente a maioria das mães para a opção de curso técnico ou superior.

Com relação ao recebimento de alguns benefícios por parte do governo no intuito de ajudar nos cuidados diários, constatou-se que a maioria das mães não recebe benefício do governo $(77,2 \%)$. Porém, das mães que recebem benefício oriundos de entidades governamentais, a maioria recebe o de prestação continuada (BPC) oferecido pelo governo federal (19\%), e foi apontado também a existência de um benefício da oriundo da prefeitura municipal equivalente a meio salário mínimo $(1,3 \%)$, bem como bolsa família $(1,3 \%)$ e auxílio à familiar com deficiência $(1,3 \%)$.

No que tange à renda salarial, as mães responderam de acordo com o valor da faixa salarial familiar. Isto posto, a faixa com maior percentual de concentração é de 3 a 4 salários mínimos, com $43 \%$, seguido pela faixa de 1 a 2 salários mínimos com 36,7\%. O extrato de 6 a 8 salários mínimos apresenta um percentual de $11,4 \%$ e a faixa de 9 a 10 e mais de 10 salários mínimos com um percentual de 8,9\% da amostra.

Após foi identificado à quantidade de filho de cada mãe e o nível de autismo de cada um dos filhos. A maioria das mães tem apenas um filho com autismo, representando $92,4 \%$ da amostra e um pequeno percentual de 7,6\% com dois filhos. Ressalta-se que não teve nenhuma mãe com 3 ou mais filhos autistas.

No que diz respeito ao nível de autismo dos filhos, averiguou-se que o nível 1 (leve) é o que possui maior incidência, com 67,1\%. Em seguida vem as crianças com o nível 2 (moderado), com 30,6\% e, por fim, 2,3\% com o nível 3 (mais severo).

Para compreender um pouco mais a possível realidade das mães, indagou-se, também, sobre a quantidade de terapia realizada por cada uma das crianças e, para tanto, descobriu-se que a maior parte das mães realizam tratamento terapêutico dos seus filhos, com $75,9 \%$, enquanto $24,1 \%$ não realizam tal ação. Visando saber mais sobre o motivo de não estar realizando o tratamento, nesta questão pediu-se para não levar em consideração as interrupções oriundas da pandemia (COVID), o que não surtiu efeito direto, pois $31,6 \%$ das respondentes mencionaram isso como o motivo da criança não estar realizando as terapias. Porém, quando observado os outros motivos, a maior incidência, ou seja $42,1 \%$, aponta que não está realizando o tratamento por não conseguir atendimento público e também por não ter condições de realizar o tratamento de maneira particular.

Porém, para as mães que informaram que os filhos realizam terapia, questionou-se quantas vezes isso ocorre na semana, afinal, parte-se da premissa que a gestão da carreira profissional com o autismo do filho está muito ligada a quantidade de dias que as mesmas acontecem, pois crianças com mais dias de intervenções terapêuticas fazem com que as mães tenham um maior comprometimento com o filho e seu tratamento.

Diante do exposto, observou-se que a maioria das crianças tem terapia 1 vez na semana, com 30\% das respostas, o que permite concluir que as mães possivelmente tenham mais liberdade para conciliar a carreira com as terapias. Logo após surge a quantidade de 2 vezes na semana, com 28,3\%. Apesar de comprometer mais dias da semana com terapias, imagina-se ainda ser possível conciliar a carreira com as terapias. Contudo, $21,7 \%$ das mães afirmaram que seus filhos fazem terapias 4 vezes na semana, o que neste caso se elas não tiverem uma rede de apoio, fica difícil conciliar tais situações.

Para que a mãe possa dividir as responsabilidades e ainda ter a oportunidade de poder investir em sua carreira, fez-se o cruzamento de dados considerando as variáveis rede de apoio e quantidade de terapias. Desta forma, apurou-se que $46,7 \%$ delas são responsáveis por levar o filho na terapia e possui apoio familiar nesta tarefa, o que ajuda para poder conciliar a carreira profissional e o tratamento de autismo do filho. Em seguida, verificou-se que 41,7\% das mães respondentes são as únicas responsáveis por levar o filho nas terapias, o que mostra que um percentual expressivo que sinaliza a dificuldade de se conciliar suas carreiras com as terapias. Por fim, $10 \%$ da amostra sinaliza que apenas os membros de família são responsáveis por levar a criança na terapia, assim como nenhuma das mães possui babá ou cuidador para o apoio das terapias. 
Ainda na dimensão terapias, questionou-se se elas são realizadas no sistema pública ou na iniciativa privada. Como resultado, evidenciou-se que a maioria das mães realiza atendimento privado com $46,6 \%$, enquanto $39,7 \%$ utiliza a esfera pública. Apenas uma pequena parcela de 13,7\% realiza atendimento em ambas as modalidades.

Com relação ao atendimento na iniciativa privada, foi indagado para as respondentes que tipo de atendimento costuma ser realizado. O propósito desta pergunta era o de entender a natureza do atendimento privado, pois sabe-se que eles podem ser feitos por meio de planos de saúde - cuja maioria das empresas disponibilizam para seus funcionários -; por convênios de desconto - no qual se paga uma mensalidade para se ter desconto no valor de consultas e exames; ou particular. Nesta questão foi deixado mais de uma opção, no qual a soma dos percentuais fica diferente de $100 \%$. De acordo com o resultado, $80 \%$ das mães pagam de maneira particular algum atendimento do filho, depois vindo os planos de saúde com 51,4\% e, por último, um pequeno percentual dos atendimentos pelo convênio de desconto.

Em síntese, ao se interpretar estas distribuições e as apontadas nos parágrafos anteriores, pode-se imaginar que além dos custos normais inerentes à criação de um filho, as mães com filhos autistas necessitam de uma fonte de renda compatível para suprir as necessidades inerentes à saúde dos mesmos.

Em paralelo, considerou-se também a questão educacional das crianças, sendo que 93,7\% das mães têm os filhos matriculados em alguma instituição educacional. Já 6,3\% não possuem uma instituição educacional para seus filhos. Isso significa um tipo de ajuda complementar para as mães, pois além de possibilitar momentos de convívio com outras crianças, o que por si só já é algo positivo, elas podem crescer recebendo algum tipo de instrução que permita um entendimento mais claro de mundo - dependendo do nível. Por conseguinte, pode-se interpretar esta informação como uma oportunidade para que as mães tenham não apenas onde deixar seus filhos, mas que ao mesmo tempo possam concentrar suas energias e atenção para trabalhar e investirem nas suas carreiras profissionais.

Para poder validar a interpretação apresentada no parágrafo anterior, questionou-se o tempo que as crianças passam na instituição. Os valores apresentados representam o cômputo de horas independente se elas frequentam mais de uma instituição:

Tabela 1 - Horas passadas na instituição educacional.

\begin{tabular}{c|c|c}
\hline Descrição & Frequência Absoluta & Frequência Relativa \\
\hline 4 horas & 28 & $37,8 \%$ \\
\hline 5 horas & 21 & $28,4 \%$ \\
\hline 6 horas & 7 & $9,5 \%$ \\
\hline 7 horas & 2 & $2,7 \%$ \\
\hline 8 horas & 10 & $13,5 \%$ \\
\hline 9 horas & 5 & $6,8 \%$ \\
\hline 10 horas & 1 & $1,4 \%$ \\
\hline Total & $\mathbf{7 4}$ & $\mathbf{1 0 0 \%}$ \\
\hline
\end{tabular}

Fonte: Dados primários (2020).

Como apresentado na Tabela 1, mais da metade das crianças passam de 4 a 5 horas nas instituições educacionais, o que reforça a confirmação da crença na qual o tempo que elas passam na escola pode contribuir para gerar tempo estratégico visando o desenvolvimento pessoal e profissional das mães, como também a instituição educacional é um aliado para o desenvolvimento comportamental da criança, ajudando a torná-la mais independente.

Com o objetivo de se analisar melhor o cenário educacional por causa dos impactos das decisões governamentais em função da pandemia (COVID), questionou-se se as mães teriam apoio familiar quando o filho não está na escola. A análise das respostas permite identificar que a maior parte das mães possui apoio familiar, com 48,1\%, o que mais uma vez contribui para a interpretação de que elas podem dedicar boa parte de seu tempo para trabalhar ou investir em suas carreiras. Porém, o limiar 
é muito tênue, tendo em vista que ainda há uma grande parcela das mães, com $46,8 \%$, que não tem nenhum apoio para poder cuidar dos filhos na ausência da instituição escolar.

Como forma de validação da percepção existente, obtiveram-se dados que permitiram entender a relação entre o grau de formação e a atuação profissional. Para poder identificar a trajetória profissional das mães de autistas, levou-se em consideração a situação atual das 58 que responderam possuir ensino superior ou curso técnico na pesquisa. Pelo verificado, 53,4\% das mães não estão trabalhando na área de formação e 46,6\% estão. Isso pode ser resultante da dificuldade de se conseguir inserir no mercado de trabalho, de certos tipos de preconceitos e da disputa inerente a qualquer tipo de emprego, onde a qualificação profissional costuma decidir quem entra ou não.

Analisando a questão ainda pela ótica da empregabilidade, o que se percebe é que muitas argumentam que em função das dificuldades decorrentes de tal situação de vida, o que importa é conseguir uma fonte de renda que possibilite a geração de recursos que permitam a continuidade dos tratamentos.

Em complemento ao que foi exposto no parágrafo anterior, se for analisada tal argumentação com os dados apresentados a seguir, verifica-se que 40,5\% das respondentes sequer trabalham, o que nem sempre é por opção, mas por causa das circunstâncias de vida relacionadas com as necessidades de cuidados dos filhos autistas, cargas de terapias, auxílios diversos, etc.

Em paralelo, outro fator que pode elucidar estes números é a própria carga horária de trabalho, porque as empresas têm necessitado o cumprimento de uma jornada de 8 horas diárias, o que grande parte das respondentes não consegue atender plenamente. Com isso, o resultado tende a ser um só: elas largarem suas profissões e carreiras.

Tabela 2 - Carga horária de trabalho atual.

\begin{tabular}{l|c|c}
\hline Descrição & Frequência Absoluta & Frequência Relativa \\
\hline Não Trabalho & 32 & $40,5 \%$ \\
\hline 20 horas & 7 & $8,9 \%$ \\
\hline 30 horas & 13 & $16,5 \%$ \\
\hline 36 horas & 3 & $3,6 \%$ \\
\hline 40 horas & 8 & $10,2 \%$ \\
\hline 44 horas & 11 & $13,9 \%$ \\
\hline 60 horas & 2 & $2,5 \%$ \\
\hline Mais de 60 horas & 2 & $2,5 \%$ \\
\hline Aposentada & 1 & $1,3 \%$ \\
\hline Total & $\mathbf{7 9}$ & $\mathbf{1 0 0 \%}$ \\
\hline
\end{tabular}

Fonte: Dados primários (2020).

Teoricamente as mães que trabalham jornadas de 6 horas diárias ou menos por semana provavelmente conseguem conciliar melhor as terapias com o trabalho.

Após essa primeira conclusão, verificou-se depois a ocupação profissional de cada mãe para poder avaliar um pouco melhor sobre a estrutura profissional atual. Os dados obtidos se mostraram muito interessantes. Verifica-se que $38 \%$ das mães têm por ocupação ser dona de casa, e é representado com a maior parte das mães, sendo este o reflexo da influência do diagnóstico sobre a trajetória profissional das mães, que por vezes têm que largar o emprego para cuidar do filho e seus cuidados. Logo após vem a servidora pública, com $24,1 \%$, pela estabilidade e benefícios existentes para cuidar dos filhos com deficiência, o que facilita para que consiga manter uma carreira e conciliar com as terapias. Logo depois vem as mães assalariadas, que representam $19 \%$ do total, seguida pelas mães autônomas com 12,7\%. 
Um detalhe: quando perguntadas sobre os tipos de auxílio recebidos, a maioria das mães respondeu que não $(84,8 \%)$ possuem auxílio para cuidados dos filhos. Porém, 15,2\% informaram que suas empresas têm benefícios para cuidar dos seus filhos autistas, sendo os benefícios descritos: redução de carga horária, meio salário mínimo, um salário mínimo, reembolso da educação estendida e flexibilidade. Diante do explicitado, deve-se ponderar que os chamados benefícios se encontram na linha de filosofia dos espontâneos, o que por si só demonstra e valoriza a importância de se encontrar empresas que adotem tal postura.

Uma curiosidade a ser destacada é que na pesquisa existia um campo denominado "empresária" e na amostra analisada não se identificou qualquer registro para tanto. Isso mostra, de certa forma, que quando as mães de autistas empreendem, pois o autônoma pode ter sido compreendido como tal, elas provavelmente tenham optado pela modalidade informal ou então não apresentam um quadro funcional que permita que elas visualizem isso como um ato de empreendedorismo.

Voltando para os dados apresentados, aparecem por último as mães estudantes e a que realizam trabalhos temporários, que mesmo com baixo percentual assinalado, tendem a gerar convicções frente ao que foi ponderado até o momento.

No que se refere ao conhecimento das possibilidades de se realizar os trabalhos em situações de pandemia (COVID), pode-se constatar que o cenário é bem interessante, até mesmo porque na época em que a pesquisa foi aplicada, os municípios participantes oscilavam entre lockdown ou não, assim como muitos dos trabalhos existentes não necessariamente eram considerados como serviços essenciais e, por isso, acabavam por impelir com que algumas mães voltassem a trabalhar presencialmente, aumentando o risco de contágio e, ao mesmo tempo, de angústia frente aos dissabores de uma decisão desta natureza.

Foi verificada com as mães a modalidade de trabalho realizado no momento:

Tabela 3 - Modalidade de trabalho atual.

\begin{tabular}{l|c|c}
\hline \multicolumn{1}{c|}{ Descrição } & Frequência Absoluta & Frequência Relativa \\
\hline Totalmente na empresa & 23 & $50 \%$ \\
\hline Totalmente Home Office & 11 & $24 \%$ \\
\hline Trabalho externo & 2 & $4 \%$ \\
\hline Parte do trabalho Home Office & 8 & $17 \%$ \\
\hline Parte do trabalho externo & 1 & $2 \%$ \\
\hline Parte do trabalho Home Office e parte do trabalho externo & 1 & $2 \%$ \\
\hline Total & $\mathbf{4 6}$ & $\mathbf{1 0 0 \%}$ \\
\hline
\end{tabular}

Fonte: Dados primários (2020).

A metade das respondentes, ou seja $50 \%$, tiveram que trabalhar in loco no seu ambiente de trabalho, o que pode ser compreendido como um ponto dificultador, principalmente no momento de pandemia, no qual as crianças estão sem aulas, e as instituições estão sem atendimento para as crianças com deficiência. Logo depois vem o trabalho totalmente Home office, com $24 \%$ das mães nesta modalidade, depois vem parte do trabalho em home office, com 17\%, e com percentual menor, vem o trabalho externo, parte do trabalho externo e parte do trabalho em home office e externo.

Foi verificado se a empresa em que as mães trabalham tem uma política diferenciada para as crianças com autismo. A maioria das mães, com $82,6 \%$, afirmaram que não encontraram isso. Todavia, 17,4\%, afirmaram que têm e que tais políticas estão calcadas nos seguintes pontos: auxílio na luta pela causa autista, redução da carga horária sem prejuízo da remuneração, direito de levar os filhos nas terapias, redução de carga horária e licença especial. 


\subsection{Mudanças ocorridas nas trajetórias profissionais das mães após o diagnóstico de autismo do filho}

Neste tópico será avaliado o impacto do diagnóstico do autismo na trajetória profissional das mães de autistas.

Para poder compreender o impacto do diagnóstico na trajetória profissional das mães de autista, foi questionado se no momento do recebimento do diagnóstico estavam trabalhando, estudando, realizando ambos ou nenhum dos dois. Foi evidenciado que $62 \%$ das mães estavam trabalhando no momento do diagnóstico. Logo após vem as mães que não estavam nem trabalhando e nem estudando com 20,3\%, seguidos das mães que estavam trabalhando e estudando, com 15,2\% e um pequeno percentual estava somente estudando com $2,5 \%$.

Como verificado acima, 79,7\% (63) das mães estavam trabalhando e/ou estudando no momento do diagnóstico. Contemplou-se a análise relacionada a possibilidade das mães pararem de estudar e/ou trabalhar em função do diagnóstico de autismo dos filhos. O resultado foi considerado muito promissor, pois a maioria, 68,3\% (43), não precisou interromper nem os estudos e nem trabalho, mas um percentual considerável de 23,8\% (15) teve que interromper seu trabalho para poder se dedicar aos cuidados dos filhos, enquanto $4,8 \%$ (3) tiveram que interromper os estudos, e um percentual menor de $3,2 \%$ (2) teve que interromper os estudos e o trabalho.

Logo depois, para as vinte mães que informaram ter interrompido o trabalho e/ou estudo, procurou-se conhecer se elas conseguiram retornar e o tempo em que ficaram paradas após o diagnóstico do filho:

Tabela 4 - Tempo de interrupção no estudo e/ou trabalho.

\begin{tabular}{l|c|c}
\hline Descrição & Frequência Absoluta & Frequência Relativa \\
\hline Menos de 1 ano & 1 & $5 \%$ \\
\hline 1 ano & 1 & $5 \%$ \\
\hline 2 anos & 2 & $10 \%$ \\
\hline 3 anos & 2 & $10 \%$ \\
\hline 4 anos & 1 & $5 \%$ \\
\hline 5 anos & 4 & $20 \%$ \\
\hline 7 anos & 1 & $5 \%$ \\
\hline 8 anos & 1 & $5 \%$ \\
\hline Desde o diagnóstico até o momento & 7 & $35 \%$ \\
\hline Total & $\mathbf{2 0}$ & $\mathbf{1 0 0 \%}$ \\
\hline
\end{tabular}

Fonte: Dados primários (2020).

Verifica-se que 35\% das mães não retornaram ao trabalho depois do diagnóstico de autismo do filho. Das que retornaram a trabalhar, a maioria demorou em torno de 5 anos para voltar ao mercado de trabalho. Este resultado tende a sinalizar algumas dificuldades existentes para tanto, tais como: a) A dificuldade do mercado em realocar uma mãe com um filho deficiente; b) O preconceito que se tem sobre a mãe conseguir conciliar o emprego com as terapias; c) A falta de conhecimento/experiência para o cargo devido ao tempo que se ficou fora do mercado ou; d) $\mathrm{O}$ de conciliar a rotina de trabalho e cuidados do filho autista.

Questionadas se realizaram alguma atividade que gerasse renda para poder continuar ajudando no sustento da casa, a maior parte das mães afirmou que não realizou nenhuma atividade com renda, sendo reflexo da rotina de terapias e cuidados e ensinamentos que devem ocorrer com as crianças autistas. Para as mães que realizaram algum tipo de atividade, destacam-se: faxina, artesanato, trabalho extra, trabalho free, manicure e trabalhos de estética, recepção, venda de doces e aula nas universidades.

Aproveitou-se a oportunidade para indagar se estas atividades remuneradas tinham ligação com a área de formação das mães. A maioria das mães informou que sim $(55,6 \%)$, cuja situação possibilitou o aproveitamento do conhecimento ganho 
para poder auxiliar na renda da família, assim como podendo ter uma maior flexibilidade para levar os filhos nas terapias. No entanto, 33,3\% informaram não estar realizando nenhuma atividade ligada a sua área de formação. Em complemento, visualizou-se que 38\% das mães não pararam de trabalhar, 29\% continuaram trabalhando entre 1 a 4 anos, 12,7\% entre 5 a 8 anos e $19 \%$ sequer voltaram.

De forma mais diretiva, indagou-se para as mães se elas achavam que o diagnóstico de autismo do filho havia influenciado em sua trajetória profissional. O resultado foi considerado interessante, pois para 35,4\% delas, o diagnóstico não influenciou, enquanto para a maioria - 64,6\% - informou que sim, influenciou. Os relatos sobre o que mudou foram os seguintes: a) Não consegue cargo de chefia; b) Falta de tempo para investir no profissional, pois dedica o tempo fora do trabalho ao filho; c) Começou uma renda extra em casa pra poder ter mais flexibilidade; d) Não voltou mais ao mercado de trabalho; e) Carga emocional grande que afeta o físico e fica muito cansada; f) Não se concentra para o trabalho pelas preocupações com o tratamento do filho; g) Dedicação ao filho e realização de cursos de autismo; h) Mudança de emprego com uma carga horária menor para levar o filho nas terapias; i) Mudou a área de estudos e os planos profissionais e; j) Mães que ainda não superaram o diagnóstico e estão com a carreira parada.

Diante disso, verificou-se a existência de perdas de oportunidades de estudo e trabalho em função do diagnóstico do filho. Para conhecimento, $54,4 \%$ das mães entenderam que sim, a perda ocorreu, enquanto 45,6\% acreditam não ter perdido algo em função do diagnóstico de autismo do filho. Essa resposta também foi considerada muito interessante, pois nota-se que a diferença entre os percentuais não é tão expressiva. Apresenta-se, em seguida, o detalhamento das oportunidades consideradas como perdidas:

Figura 1 - Oportunidade perdida em função do diagnóstico de autismo do filho.

\begin{tabular}{|r|r|l|l|l|l|}
\hline Crescimento profissional \\
Estudar para concurso \\
Várias \\
Ingresar na área de carreira desejada
\end{tabular}

Fonte: Dados primários (2020).

As maiores perdas relatadas estão relacionadas diretamente ao trabalho e, em seguida, relacionadas à formação profissional. As mães afirmam, inclusive, que o motivo que fez com que elas perdessem essas oportunidades estava ligado à dedicação que precisava ser dispensada para o tratamento do filho e que, com um emprego, não conseguiriam acompanha-los à contento. Outrossim, houve ponderações que destacaram a falta de uma rede de apoio para poder ficar com o filho, o desgaste físico e mental em conciliar tais atividades, o medo de deixar o filho aos cuidados de alguém que talvez não dê a devida atenção, a falta de dinheiro, dentre outros. 
Diante do que foi exposto por elas, a dúvida ficou concentrada na mudança causada após a confirmação do diagnóstico. Para tanto, investigou-se o possível êxito em conciliar a carreira profissional e os afazeres maternos. As respostas foram as seguintes:

Tabela 5 - Retomada da carreira profissional.

\begin{tabular}{l|c|c}
\hline Descrição & $\begin{array}{c}\text { Frequência } \\
\text { Absoluta }\end{array}$ & $\begin{array}{c}\text { Frequência } \\
\text { Relativa }\end{array}$ \\
\hline Consegui manter & 41 & $51,9 \%$ \\
\hline Mudei de área & 2 & $2,5 \%$ \\
\hline Parei e não retornei as atividades & 28 & $35,5 \%$ \\
\hline Parei por um tempo e depois retornei à minha carreira profissional & 4 & $5,1 \%$ \\
\hline Parei por um tempo e retornou em outra área profissional & 4 & $5,1 \%$ \\
\hline Total & $\mathbf{7 9}$ & $\mathbf{1 0 0 \%}$ \\
\hline
\end{tabular}

Fonte: Dados primários (2020).

A maioria das mães conseguiu manter sua carreira profissional após o diagnóstico, com 51,9\%, enquanto 34,2\% informaram que não retornaram as atividades profissionais após o diagnóstico do filho, teve uma pequena parcela que parou e depois retornou para a mesma carreira profissional, enquanto outras pararam e retornaram em outra carreira.

Apesar de que a maioria conseguiu manter sua carreira, várias expuseram que aproveitaram o tempo paradas para iniciar novos estudos ou mudar completamente de área. Isso ficou comprovado ao se analisar as respostas delas, onde algumas confirmam que se especializaram em autismo, outras iniciaram uma nova graduação ou pós-graduação, outras foram para a área de palestras, dentre outras. Como retorno pelo investimento realizado, 72,4\% destas mães manifestaram que o maior ganho estava diretamente relacionado com o filho, pois seja por intermédio da geração de novos conhecimentos específicos à doença, ou por novas oportunidades de trabalho, o tempo e o recurso financeiro gerado fez com que a percepção das mesmas relacionada a uma tomada de decisão trouxesse uma satisfação ainda maior.

\subsection{Similaridades e disparidades entre as trajetórias profissionais das mães de autistas}

Realizada toda análise do questionário e identificado a diferença de escolhas tomadas pelas mães, este tópico tratará sobre as similaridades e disparidades de escolhas das mães de autistas. Para tanto, apresenta-se o quadro a seguir:

Quadro 2 - Similaridades e Disparidades.

\begin{tabular}{|l|l|}
\hline \multicolumn{1}{|c|}{ Similaridades } & \multicolumn{1}{|c|}{ Disparidade } \\
\hline $75,9 \%$ das mães têm filhos realizando terapias. & $\begin{array}{l}10,1 \% \text { das mães não realizam a terapia no filho, pois não } \\
\text { conseguiram atendimento público e não tem condições de } \\
\text { realizar particular. }\end{array}$ \\
\hline $30 \%$ das mães realizam apenas uma vez na semana terapias. & $\begin{array}{l}5 \% \text { das mães leva o seu filho 5 ou mais vezes na semana o filho } \\
\text { na terapia. }\end{array}$ \\
\hline $\begin{array}{l}48,1 \% \text { das mães têm o apoio da família na falta de instituição } \\
\text { escolar. }\end{array}$ & $\begin{array}{l}46,8 \% \text { das mães não têm o apoio da família na falta da } \\
\text { instituição escolar; }\end{array}$ \\
\hline $\begin{array}{l}30 \text { mães informaram nunca ter parado de trabalhar após o } \\
\text { diagnóstico. }\end{array}$ & $\begin{array}{l}12 \text { mães entendem que tem perdido oportunidades de trabalho } \\
\text { após o diagnóstico. }\end{array}$ \\
\hline $\begin{array}{l}\text { A maioria das mães acredita que para se desenvolver } \\
\text { profissionalmente precisam de tempo, e entendem como } \\
\text { dificultadores da sua carreira a ausência de tempo, dificuldade para } \\
\text { alguém ficar com seu filho e recursos financeiros. }\end{array}$ & $\begin{array}{l}32 \text { mães informaram ter realizado algum curso após o } \\
\text { diagnóstico de autismo do filho. }\end{array}$ \\
\hline
\end{tabular}

Fonte: Dados primários (2020). 
Primeiro ponto encontrado pelas mães foi com relação ao tratamento, sendo que 75,9\% das mães informaram que seus filhos realizam terapias, sejam elas pela rede pública ou particular. O que se pode concluir a partir daqui é que o tratamento do autista é eficaz quando realizadas as terapias comportamentais. Porém, como uma disparidade da trajetória profissional das mães, identificou-se que $10,1 \%$ das mães não realiza a terapia do seu filho e o principal problema estava relacionado ao fato de não conseguir o atendimento de forma pública e gratuita, assim como também não ter como pagar pelo tratamento particular. Aqui se conclui preliminarmente que tal fator implica diretamente na carreira das mães, pois atinge o lado emocional das mesmas, afetando a continuidade das suas escolhas individuais em função da condição de vida dos filhos.

Da mesma forma, observou-se como similaridade que a maioria das mães tem os filhos realizando terapia apenas uma vez na semana, o que torna mais acessível para que as mães possam trabalhar e construir uma carreira ao realizar o tratamento do filho. Em oposição, torna-se um fator de disparidade, onde existe uma parcela de $5 \%$ de mães que leva o filho 5 ou mais vezes por semana na terapia, o que, neste caso, dificulta a mãe a ter uma trajetória profissional se não tiver uma rede de apoio para poder levar o filho as terapias.

Com relação a rede a apoio, à medida que $48,1 \%$ das mães informaram ter ajuda da família quando não tem aula, verificou-se que outros 48,8\% não conta com tal suporte, trazendo impactos para as mulheres que desejarem ter uma carreira, pois acabará pesando na decisão do que é considerado o mais importante para elas: a carreira, que garante sustento a família, ou o tratamento do filho, que permitirá que ele se torne independente.

Cerca de 30 mães da amostra tem trajetórias similaridades com a sua relação com o trabalho, e, desde o diagnóstico nunca pararam de trabalhar construindo a sua carreira. No entanto, com uma disparidade desta realidade, 12 mães informaram que perderam oportunidades de trabalho após o diagnóstico devido ao fato de terem um filho autista.

No levantamento dos fatores que faltavam para o desenvolvimento profissional, bem como dos dificultadores para que as mães pudessem se desenvolver profissionalmente, os discursos formam muito similares. Para tanto, alegou-se que o tempo ou a ausência dele se tornou um empecilho para que elas crescessem profissionalmente. Além desse fator, que foi o maior percentual, as mães colocaram que a dificuldade de alguém para cuidar do filho, além do recurso financeiro, vem impedindo para que se desenvolvam profissionalmente.

Porém, teve uma parcela considerável de mães que mesmo diante das dificuldades enfrentadas após o diagnóstico de autismo, conseguiu realizar algum curso para o seu crescimento profissional, mostrando que é possível enfrentar algumas barreiras para se desenvolverem.

\section{Considerações Finais}

Este trabalho tinha como problema responder a seguinte questão: Como o diagnóstico de autismo do filho influenciou a trajetória profissional das mães que residem na Grande Florianópolis? Em função disso foi elaborado o objetivo geral desta pesquisa que é compreender a influência do diagnóstico de autismo do filho sobre a trajetória profissional das mães que residem na Grande Florianópolis.

Para a consecução mais completa deste trabalho, objetivou-se mapear o perfil profissional das mães de autistas que residem na região da Grande Florianópolis. Assim sendo, foram verificados e apresentados alguns dados referentes ao perfil socioeconômico das mães. Além dessas informações, buscou-se conhecer melhor a realidade das mesmas quanto aos tipos de benefícios recebidos, a quantidade de filhos autistas, o grau de autismo, a quantidade de terapias realizadas por eles, qual a modalidade de atendimento, dentre outros.

Isso posto, foi possível analisar melhor as mudanças ocorridas após o recebimento do diagnóstico de autismo dos filhos, até mesmo porque diversas questões foram idealizadas e interpretadas conforme posicionamento das respostas. Tais mudanças foram detalhadas nos subitens anteriores, sendo que houve a preocupação de demonstrar a relação entre a 
escolaridade, o trabalho, às características inerentes às terapias, rede de apoio e recursos financeiros como elementos chave para a manutenção ou não das condições de carreiras existentes ou da geração de novas características para novas realidades.

Por fim, mas não menos importante, como decorrência da apresentação resumida de todos os pontos contidos da pesquisa, foi possível identificar as similaridades e disparidades da trajetória profissional das mães de autistas que residem na região da Grande Florianópolis. Para tanto, o que se concluiu é que não houveram tantas disparidades entre as respondentes, o que, logicamente não significa que tais resultados poderão ser interpretados de forma generalizada. Contudo, ficou mais evidente as condições minimamente necessárias para que as vivências possam ser menos impeditivas no que tange ao assunto carreira profissional.

A partir desse trabalho desenvolvido, recomenda-se o seguinte pontos como sugestões para trabalhos futuros: utilizar a mesma pesquisa para outros municípios da região da Grande Florianópolis; abranger o mesmo tipo de pesquisa não apenas para o autismo, mas para outras deficiências/doenças que precisam de cuidados intensivos das mães; aprofundar na pesquisa verificando aprofundar quais capacitações poderiam ser desenvolvidas para que as mães possam vir a desenvolver mais a sua carreira profissional; analisar a efetividade das ações promovidas pelos órgãos públicos no intuito de não apenas auxiliar com o suporte estrutural para as mães de crianças autistas, mas, também, o de reforçar o papel social das mesmas para a geração de novas oportunidades de empregabilidade/carreira.

\section{Referências}

Almeida, M. S. (2014). Elaboração de projeto, tcc, dissertação e tese: uma abordagem simples, prática e objetiva. (2a ed.), Atlas.

Bosa, C. A. (2006). Autismo: intervenções psicoeducacionais. Revista Brasileira de Psiquiatria, 1(28), 47-53. http://www.scielo.br/pdf/\%0D/rbp /v28s1/a07v28s1.pdf.

Borges, L. S. (2020). A influência do diagnóstico de autismo na trajetória profissional das mães da Grande Florianópolis. Trabalho de Curso de Bacharel em Administração. Universidade Federal de Santa Catarina. https://repositorio.ufsc.br/handle/123456789/218163.

Brito, A. L. P. (2020). Direito, (r)evolução e trabalho: uma discussão do papel do estado frente aos impactos da quarta revolução industrial. Dissertação de Mestrado em Direito. Centro Universitário Christus, Fhttps://repositorio.unichristus.edu.br/jspui/handle/123456789/1011.

Carvalho, M. B., \& Marcelino, C. A. A. S. (2019). Trabalho e sociabilidade. InterSaberes.

Ceribelli, H. B., \& Silva, E. R. (2017). Interrupção voluntária da carreira em prol da maternidade. Revista pensamentos contemporâneo em Administração, 11(5), 116-139. http://www.spell.org.br/documentos/ver/48642/interrupcao-voluntaria-da-carreira-em-prol-da-maternidade.

Ciampa, A. L., Melo, P., Mele, C.; \& Peixoto, A. M. M. (2014). Marketing pessoal e empregabilidade: do planejamento de carreira ao networking. Érica.

Ferreira, I. C., Costa, J. J., \& Couto, D. P. (2018). Implicações do diagnóstico de autismo para a vivência da maternidade. Revista da Graduação em Psicologia da PUC Minas, 3(5), 431-448. http://periodicos.pucminas.br/index.php/pretextos/article/view/15936/13020.

Fontura, D. S. (2015). Mães azuis, trajetórias de mães de autistas de Porto Alegre. Monografia de Bacharel em Ciências Sociais. Universidade Federal do Rio Grande do Sul.:https://lume.ufrgs.br/bitstream/handle/10183/132399/000983733.pdf?sequence=1\&isAllowed=y.

Gaiato, M. (2018). S.O.S autismo: guia completo para entender o Transtorno do Espectro Autista. nVersos.

Gaiato, M.; Teixeira, G. (2018). Reizinho autista: guia para lidar com comportamentos difíceis. nVersos.

Gil, A. C. (2018). Como elaborar projetos de pesquisa. (6a ed.), Atlas.

Grandin, T. (2015). O cérebro autista. Record.

Julião, J. R. et al. (2019). A relação entre maternidade e mercado de trabalho: um estudo sob a perspectiva de uma mãe trabalhadora. Research, Society and Development, 8(4), 1-9. https://dialnet.unirioja.es/servlet/articulo;jsessionid=4CDF28BDCB6660D25C1EE30319A7F12D.dialnet01?codigo=7164682.

Leopoldino, C. B. (2015). Inclusão de autistas no mercado de trabalho: uma nova questão de pesquisa. Revista Eletrônica Gestão \& Sociedade, 9(22), 853868. https://www.gestaoesociedade.org/gestaoesociedade/article/view/2033.

Lozada, G., \& Nunes, K. S. (2018). Metodologia científica. SAGAH.

Machado, R. A. (2018). A reinserção da mulher no mercado de trabalho no período da pós-maternidade. Trabalho de Conclusão de Curso de Bacharel em Administração. Universidade Federal do Rio Grande do Sul. https://lume.ufrgs.br/bitstream/handle/10183/184950/001080383.pdf?sequence=1\&isAllowed=y.

Mattar, F. N. (2014). Pesquisa de marketing: metodologia, planejamento, execução e análise. (7a ed.), Elsevier. 
Medina, P. F. (2016). Carreiras de profissionais que atuam em coworking: entre os novos arranjos e os velhos hábitos de trabalho. Dissertação de Mestrado em Psicologia. Universidade Federal de Santa Catarina, https://repositorio.ufsc.br/bitstream/handle/123456789/168250/34050 1.pdf? sequence $=1 \&$ is Allowed $=\mathrm{y}$.

Montenegro, M. A., Celeri, E. H. R., \& Casella, E. B. (2018). Transtorno do Espectro Autista - TEA: manual prático de diagnóstico e tratamento. Thieme Revinter Publicações.

Moura, M. (2016). Curso de direito do trabalho. (2a ed.), Saraiva.

Oliveira, D. P. R. (2018). Como elaborar um plano de carreira para ser um profissional bem-sucedido. (3a ed.), Atlas.

Opas - Organização Pan-Americana da Saúde. (2017). Folha informativa - transtorno do espectro autista. https://www.paho.org/bra/index.php?Itemid=1098.

Peixoto, A. L. A., Janissek, J., \& Aguiar, C. V. N. (2015). Autopercepção de empregabilidade. In: K P., Palacios, \& A. L. A., Peixoto, Ferramentas de diagnóstico para organizações e trabalho: um olhar a partir da psicologia. (p.p 169-181). Artmed.

Pinto, F. N. S. (2015). Duas faces da mulher contemporânea: carreira e maternidade. Dissertação de Mestrado em Psicologia. Universidade Católica do Rio de Janeiro, https://www.maxwell.vrac.puc-rio.br/colecao.php?strSecao=resultado\&nrSeq=25556@1.

Prodanov. C. C. (2013). Metodologia do trabalho científico: métodos e técnicas da pesquisa e do trabalho acadêmico. (2a ed.), Feevale.

Santos, C. M., Neto Carvalho, A., Oliveira, P., \& Andrade, J. (2019). Reforçando a contribuição social de gênero: a servidora pública qualificada versus a executiva. Revista de Administração Pública, 53(1), 101-123. http://www.spell.org.br/documentos/ver/52660/reforcando-a-contribuicao-social-de-genero--aservidora-publica-qualificada-versus-a-executiva.

Tenente, L. (2018). Aprovado em computação é um dos 488 alunos com autismo nas universidades do Brasil: 'não somos perdedores'. G1. Educação. 2 de abril. https://g1.globo.com/educacao/noticia/aprovado-em-computacao-e-um-dos-488-alunos-com-autismo-nas-universidades-do-brasil-nao-somosperdedores.ghtml

Trevizan, K. (2019). Pesquisa mostra que 30\% das mulheres deixam trabalho por causa dos filhos; homens são $7 \%$. G1. Concursos e empregos. 10 de maio. https://g1.globo.com/economia/concursos-e-emprego/noticia/2019/05/10/pesquisa-mostra-que-30percent-das-mulheres-deixam-trabalho-por-causa-dos-filhoshomens-sao-7percent.ghtml.

Volkmar, F. R., \& Wiesner, L. A. (2019). Autismo: guia essencial para compreensão e tratamento. Artmed. 